\title{
Reaction zone visualisation in swirling spray n-heptane flames
}

\author{
R. Yuan ${ }^{1, *}$, J. Kariuki $^{1}$, A. Dowlut ${ }^{2}$, R. Balachandran ${ }^{2}$, E. Mastorakos ${ }^{1}$ \\ 1: Hopkinson Laboratory, Engineering Department, Univerisy of Cambridge, CB2 1PZ \\ 2: Mechanical Engineering Department, UCL, London WC1E 7JE \\ * : Corresponding author. Email: ry235@cam.ac.uk
}

\section{Word count:}

$\begin{array}{lll}\text { Main Text: } & \text { word processor count } & =3031 \\ \text { Equations: } & & =0 \\ \text { References: } & (26+2) \times(2.3 \text { lines } / \text { reference }) \times(7.6 \text { words } / \text { line }) & =489.4 \\ \text { Tables: } & (\# 4+2 \text { lines }) \times(7.6 \text { words } / \text { line }) \times(1 \text { columns }) & =45.6 \\ \text { Figure 1: } & (69 \mathrm{~mm}) \times(2.2 \text { words } / \mathrm{mm}) \times(2 \text { column }) & =303.6 \\ \text { Figure 2: } & (70 \mathrm{~mm}) \times(2.2 \text { words } / \mathrm{mm}) \times(2 \text { column }) & =308 \\ \text { Figure 3: } & (69 \mathrm{~mm}) \times(2.2 \text { words } / \mathrm{mm}) \times(2 \text { column }) & =303.6 \\ \text { Figure 4: } & (80 \mathrm{~mm}) \times(2.2 \text { words } / \mathrm{mm}) \times(2 \text { column }) & =352 \\ \text { Figure 5: } & (58 \mathrm{~mm}) \times(2.2 \text { words } / \mathrm{mm}) \times(1 \text { column }) & =127.6 \\ \text { Figure 6: } & (105 \mathrm{~mm}) \times(2.2 \text { words } / \mathrm{mm}) \times(2 \text { column }) & =462 \\ \text { Figure 7: } & (53 \mathrm{~mm}) \times(2.2 \text { words } / \mathrm{mm}) \times(2 \text { column }) & =233.2 \\ \text { Figure 8: } & (61 \mathrm{~mm}) \times(2.2 \text { words } / \mathrm{mm}) \times(2 \text { column }) & =268.4\end{array}$

Total $=\mathbf{5 9 2 5}$ words

Colloquium: Spray and droplet combustion (7)

Alternative Colloquium: IC engine and Gas Turbine Combustion (11)

Supplemental Material: no 


\title{
Reaction zone visualisation in swirling spray n-heptane flames
}

\author{
R. Yuan ${ }^{1, *}$, J. Kariuki ${ }^{1}$, A. Dowlut ${ }^{2}$, R. Balachandran ${ }^{2}$, E. Mastorakos ${ }^{1}$ \\ 1: Hopkinson Laboratory, Engineering Department, Univerisy of Cambridge, CB2 1PZ \\ 2: Mechanical Engineering Department, UCL, London WC1E 7JE \\ * : Corresponding author. Email: ry235@cam.ac.uk
}

\begin{abstract}
Joint PLIF measurements of $\mathrm{CH}_{2} \mathrm{O}$ and $\mathrm{OH}$ were performed in a swirl-stabilized nheptane spray flame at conditions close to extinction. Simulations of laminar counterflow heptane flames at different strain rates showed that the heat release could be approximately represented by the product $\mathrm{CH}_{2} \mathrm{OxOH}$, but also that this product cannot visualise the heat release at the lean side of stoichiometry. The simulations suggest that the outline of $\mathrm{CH}_{2} \mathrm{O}$ regions in PLIF images could be an approximate indicator of the stoichiometric mixture fraction iso-line. Due to the intense turbulence and local extinction, individual PLIF images show a very variable behaviour. They indicate rich zones, reaction sheet breaks, lift-off, and they suggest that this flame is mostly of non-premixed character. The mean heat release rate as represented here is consistent with inverse Abel-transformed $\mathrm{OH}^{*}$ chemiluminescence imaging. The usefulness of this technique for spray flames is discussed.
\end{abstract}

Keywords: Extinction, swirl, formaldehyde fluorescence, heptane spray 


\section{Introduction}

Local extinction is an important limiting factor for lean combustion. Knowledge of the structure of the flame close to blow-off is important from a practical perspective, but also from the viewpoint of validating advanced turbulent combustion models. In gas turbines and industrial furnaces, the flame is virtually always stabilised by swirl. It can be argued that we know little about the fundamental processes of extinction of spray flames in recirculation zones, as we do not have the same degree of information as we do for gaseous flames [1-4]. Cavaliere et al. studied n-heptane spray flames and saw local extinction holes present along the flame sheet and randomly-occurring lift-off [5]. These observations were based on $5 \mathrm{kHz}$ OH-PLIF, which cannot reveal with certainty whether a flame is extinguished or not. In particular, the $\mathrm{OH}$ signal alone may not reveal whether the flame is of premixed character (and therefore there may be $\mathrm{OH}$ in the post-flame gases) or of non-premixed character (and therefore the $\mathrm{OH}$ is found roughly along the stoichiometric contour only).

As a second scalar for flame structure studies, formaldehyde $\left(\mathrm{CH}_{2} \mathrm{O}\right)$ has been used extensively. $\mathrm{CH}_{2} \mathrm{O}$ is produced in the low temperature oxidation process and consumed in the subsequent high temperature oxidation. Formaldehyde LIF was used for autoignition of methane jets [6], methanol, ethanol and acetone spray jet flames [7,8], and diesel fuel [9-11] and n-heptane $[11,12]$ in HCCI engines. Najm et al. [13] conducted detailed chemical kinetic computations of methane premixed flame and found that the concentration of formyl radical (HCO) is very well correlated with flame heat release rate. They also point that the production of $\mathrm{HCO}$ is directly dependent on the availability of its precursor $\mathrm{CH}_{2} \mathrm{O}\left(\mathrm{CH}_{2} \mathrm{O}\right.$

$\stackrel{\mathrm{OH}, \mathrm{H}, \mathrm{O}, \mathrm{M}}{\longrightarrow} \mathrm{HCO})$. However, as the PLIF of $\mathrm{HCO}$ is difficult for single shot imaging diagnostics when applied to fully turbulent flows due to its short fluorescence lifetime and low concentrations [13], the product of simultaneous $\mathrm{OH}$ and $\mathrm{CH}_{2} \mathrm{O}$ PLIF was considered as an alternative. Simultaneous $\mathrm{CH}_{2} \mathrm{O}$ and $\mathrm{OH}$ imaging and then taking the product $\mathrm{X}_{\mathrm{CH} 2 \mathrm{O}} \times \mathrm{X}_{\mathrm{OH}}$ 
(X being the mole fraction, taken as proportional to the PLIF signal intensity) has been used successfully as a marker of heat release in non-premixed and premixed flames [14-17]. Even when quantitative imaging has not been possible, the qualitative comparison of $\mathrm{CH}_{2} \mathrm{O}$ and $\mathrm{OH}$ regions has been very fruitful. Medwell and Dally [18] discussed formaldehyde in MILD combustion conditions, while Masri and co-workers looked at simultaneous $\mathrm{CH}_{2} \mathrm{O}$ and $\mathrm{OH}$ in jet flames of ethanol, methanol and acetone $[7,8]$ and very interesting comments on the nature of the reaction zones in these spray flames could be made.

In this paper, we use simultaneous $\mathrm{CH}_{2} \mathrm{O}$ and $\mathrm{OH}$ imaging in the stabilisation region of an n-heptane spray flame in a swirl-induced recirculation zone, a configuration of great relevance to gas turbine combustion, and in particular for flames close to the stability (i.e. extinction) limits. Our specific objectives are: (i) to examine the performance of the $\mathrm{CH}_{2} \mathrm{O}-$ $\mathrm{OH}$ technique for n-heptane; (ii) to visualise reaction zones in swirl spray flames; (iii) to examine how these zones are altered close to blow-off. The paper continues with a presentation of the experimental method, some results from laminar flame simulations, and typical images from the application of the technique.

\section{Methods}

An enclosed bluff-body swirling n-heptane spray flame was stabilized at two flow conditions: far from and close to blow-off. The burner (Fig. 1) was identical to the one examined previously by Cavaliere et al. [5], with the exception of a new atomiser giving a slightly narrower spray. Four quartz plates formed the combustion chamber of $97 \mathrm{~mm}$ width square and $150 \mathrm{~mm}$ length. The air was supplied through a $350 \mathrm{~mm}$ long circular duct of $D=37 \mathrm{~mm}$ inner diameter fitted with a conical bluff body of diameter $d=25 \mathrm{~mm}$. A $60^{\circ}$ swirler provided strong swirl at the exit, which, together with the bluff body, contributed to the establishment of a recirculation zone. For information, see Ref. [19] for velocity 
measurements in this burner for the n-heptane case, which should not be too far from the present flame due to the dominance of the air flow. A pressurized atomizer (Lechler, \#212.054.17.AC; a flow rate up to $0.45 \mathrm{~g} / \mathrm{s}$ at $5 \mathrm{bar}$ ) was fitted inside the bluff-body holder, providing a hollow cone spray profile with a nominal spray angle $60^{\circ}$.

The air flow was dried and particle-filtered and supplied by an air compressor. The heptane was supplied from a nitrogen-compressed container. Air and fuel flow rates were metered separately using an Alicat mass flow controller (MFC 5, 1000 SLPM) and a Bronkhorst liquid flow controller (LIQUI-flow, L30, 0-2 g/s). The two flow conditions studied as well as the blow-off condition are listed in Table 1.

Two $10 \mathrm{~Hz} \mathrm{Nd}$ :YAG lasers and one dye laser were used for the joint $\mathrm{CH}_{2} \mathrm{O}$ and $\mathrm{OH}$ PLIF system [20]. The OH-PLIF was excited at $283 \mathrm{~nm}$, while the $\mathrm{CH}_{2} \mathrm{O}-\mathrm{PLIF}$ was excited at $355 \mathrm{~nm}$. The fluorescence of $\mathrm{OH}$ was captured in the range of 309-375 nm with WG305 and UG11 Schott glass filters applied. The fluorescence of $\mathrm{CH}_{2} \mathrm{O}$ was captured in the range 375$610 \mathrm{~nm}$ using an intensified CCD camera through a filter set (laser line notch filter: OD>4, $17.8 \mathrm{~nm}$ FWHM, GG395 and BG 40) to eliminate scattering, flame luminosity, and soot emission interference. A $355 \mathrm{~nm}$ laser line notch filter was added to the $\mathrm{CH}_{2} \mathrm{O}$ camera to further cut-off any scattering of laser light by droplets. Because heptane (liquid and/or vapor) and PAH may also fluoresce in the range 350-600 $\mathrm{nm}[21,22]$, possible interference from fluorescence of vapor and liquid and of $\mathrm{PAH}$ could not be subtracted from the $\mathrm{CH}_{2} \mathrm{O}$ signals. Some comments on the importance of this interference are made later based on laminar flame simulations and on some preliminary experiments. The nominal resolution of the imaging system was $0.05 \mathrm{~mm} /$ pixel. The gain of the image intensifier was 30,000 FL/FC and 80,000 FL/FC for $\mathrm{CH}_{2} \mathrm{O}$ and $\mathrm{OH}$ respectively. The laser powers were $12 \mathrm{~mJ} /$ pulse for OH PLIF and $300 \mathrm{~mJ} /$ pulse for $\mathrm{CH}_{2} \mathrm{O}$ PLIF. The intensifiers were triggered off the Q switch of each laser 
with a gate of $220 \mathrm{~ns}$. The $\mathrm{CH}_{2} \mathrm{O}$ PLIF laser was triggered at $300 \mathrm{~ns}$ delay from the triggering of the $\mathrm{OH}$ laser. The laser pulse width was 10-12 ns.

Both $\mathrm{OH}$ and $\mathrm{CH}_{2} \mathrm{O}$ PLIF images were transformed to be spatially aligned with each other on a pixel-by-pixel basis. The alignment needed to be precise and followed several stages. Firstly, a target image (a grid pattern with several reference points) was taken using both cameras. Secondly, the $\mathrm{CH}_{2} \mathrm{O}$ image was mirrored and the corresponding coordinates of the same reference point were identified. Thirdly, a transformation matrix relating the two sets of coordinates was computed and then used to map the $\mathrm{OH}$ images onto the coordinates system of the $\mathrm{CH}_{2} \mathrm{O}$ images. The images were further processed via Matlab with background subtraction, laser profile correction, $3 \times 3$ median filtering, and a threshold below which the signal was put to zero. The product $\mathrm{CH}_{2} \mathrm{O} \times \mathrm{OH}$ was then calculated and plotted as indicator of local reaction zone. 400 images were recorded for each flow condition.

Finally, a laminar counterflow diffusion flame was simulated using Cosilab [23] with a detailed n-heptane mechanism [24]. The main species as well as the heat release were obtained for a range of strain rates and used as a reference for the joint $\mathrm{CH}_{2} \mathrm{O}-\mathrm{OH}$ PLIF measurement.

\section{Results and discussion}

\subsection{Laminar flame simulations}

Figures 2 to 4 show results from the counterflow non-premixed flame calculations for two strain rates in terms of mole fractions $(\mathrm{X}) v s$. mixture fraction $(\xi) . \mathrm{C}_{2} \mathrm{H}_{2}$ is plotted here as an indicator of soot precursors. Formaldehyde is present in the fuel-rich region, with $\mathrm{X}_{\mathrm{CH} 2 \mathrm{O}}$ increasing from $\xi=1$ toward the stoichiometric $\xi_{\text {st }}\left(\xi_{\mathrm{st}}=0.062\right.$ for heptane), decreases sharply close to $\xi_{\mathrm{st}}$, and is not present at all in the lean side. In contrast, $\mathrm{X}_{\mathrm{OH}}$ peaks near $\xi_{\mathrm{st}}$ just before the temperature and the formaldehyde peaks. At the higher strain rate shown, $\mathrm{X}_{\mathrm{CH} 2 \mathrm{O}}$ reaches 
its maximum around $\xi=0.4$, and the values are higher compared to the low strain rate. $\mathrm{C}_{7} \mathrm{H}_{16}$ and $\mathrm{C}_{2} \mathrm{H}_{2}$ are present in the fuel rich region, but the overlap between these species and $\mathrm{OH}$ is minor. This suggests that any fuel or $\mathrm{PAH}$ fluorescence will not coincide with the $\mathrm{OH}-$ containing region.

Figure 3 shows the $\mathrm{OH}$ and $\mathrm{CH}_{2} \mathrm{O}$ normalised by their peak values and includes the similarly normalised heat release rate (HRR). It can be seen that the HRR curve contains the curve showing the product $\mathrm{X}_{\mathrm{CH} 2 \mathrm{O}} \times \mathrm{X}_{\mathrm{OH}}$ (Fig. 3a). The reaction pathway analysis shows that high percentage of $\mathrm{CH}_{2} \mathrm{O}$ originates from the decomposition of the methoxy redical $\left(\mathrm{CH}_{3} \mathrm{O}+\mathrm{M}=>\mathrm{CH}_{2} \mathrm{O}+\mathrm{H}+\mathrm{M}\right)$ and from $\mathrm{CH}_{3}\left(\mathrm{CH}_{3}+\mathrm{O}=>\mathrm{CH}_{2} \mathrm{O}+\mathrm{H}\right)$. Also, formaldehyde is consumed by $\mathrm{H}$-atom abstraction reaction mainly through the reaction $\mathrm{CH}_{2} \mathrm{O}+\mathrm{H}=>\mathrm{HCO}+\mathrm{H}_{2}$ and $\mathrm{CH}_{2} \mathrm{O}+\mathrm{OH}=>\mathrm{HCO}+\mathrm{H}_{2} \mathrm{O}$. At low strain rates, the reaction $\mathrm{CH}_{3}+\mathrm{O}=>\mathrm{CH}_{2} \mathrm{O}+\mathrm{H}$ and $\mathrm{CH}_{3} \mathrm{O}+\mathrm{M}=>\mathrm{CH}_{2} \mathrm{O}+\mathrm{H}+\mathrm{M}$ is seen approximately in the region $\xi=0.066$ to $\xi=0.097$, and the reaction $\mathrm{CH}_{2} \mathrm{O}+\mathrm{OH}=>\mathrm{HCO}+\mathrm{H}_{2} \mathrm{O}$ is mostly observed in mixture fraction space from $\xi=0.070$ to $\xi=0.099$. This region correlates well with the product $\mathrm{X}_{\mathrm{CH} 2 \mathrm{O}} \times \mathrm{X}_{\mathrm{OH}}$ region. However, due to the consumption of $\mathrm{CH}_{2} \mathrm{O}$ in the lower mixture fraction region, the discrepancy between HRR and the product $\mathrm{X}_{\mathrm{CH} 2 \mathrm{O}} \times \mathrm{X}_{\mathrm{OH}}$ is high and the heat release rate comes mainly from other reactions (such as $\mathrm{CO}+\mathrm{OH}=>\mathrm{CO}_{2}+\mathrm{H}, \mathrm{HO}_{2}+\mathrm{OH}=>\mathrm{H}_{2} \mathrm{O}+\mathrm{O}_{2}$ ). Thus, at low strain rate, the $\mathrm{HRR}$ is not quantitatively represented by the product $\mathrm{CH}_{2} \mathrm{O} \times \mathrm{OH}$ : the latter could only contribute around $50 \%$ of the true HRR. In contrast, at high strain rate, the two quantities are quite close. A further observation is that the $\mathrm{OH}$ peaks at the lean side of the HRR peak, while for both low and high strain rates the peak $\mathrm{CH}_{2} \mathrm{O} \times \mathrm{OH}$ coincides with the HRR peak. Unlike the strong variation of $\mathrm{CH}_{2} \mathrm{O}$ with strain rate, the $\mathrm{OH}$ curve and levels do not vary too much, although a decrease in the peak $\mathrm{OH}$ is evident. Finally, Fig. 4 shows the normalised HRR plotted vs. the normalised $\mathrm{CH}_{2} \mathrm{O} \times \mathrm{OH}$ and $v$ s. the normalised $\left(\mathrm{CH}_{2} \mathrm{O}+\mathrm{C}_{7} \mathrm{H}_{16}\right) \times \mathrm{OH}$ for various strain rates. It is evident that for high strain rate the correlation is high and that there 
is likely no effect from any fuel fluorescence. As the strain rate decreases, it is evident that the product underestimates the heat release, however it can still be used as a spatial marker of the location of a large fraction of the heat release.

\subsection{Instantaneous $\mathrm{CH}_{2} \mathrm{O} \times \mathrm{OH}$ images}

Figure 5 shows an image obtained in un-ignited flow with the fuel running and an example of reacting flow image, both captured by the $\mathrm{CH}_{2} \mathrm{O}$ camera. The inert flow image suggests that the $\mathrm{CH}_{2} \mathrm{O}$ images contain some information from the droplets. This is not likely to be Mie scattering, as the laser wavelength has been filtered out. The droplet-like shape of the high intensity regions suggests fluorescence of heptane from the liquid phase, but the intensity is not very high. Considering the density ratio between vapour and liquid suggests that the fuel vapour is not likely to be picked up by the system. The flame images are usually smooth, but occasionally contain similar bright circular spots: see, for instance, the circled spot in Fig. 5b. These are thought to originate from fuel droplets. The percentage of images showing droplet-like shapes in the dataset is small (around 10\%) and such images are removed before the calculation of averages. In addition, such droplet-like regions virtually always do not overlap with the $\mathrm{OH}$ image.

Figure 6 presents a few typical $\mathrm{OH}, \mathrm{CH}_{2} \mathrm{O}$, and $\mathrm{CH}_{2} \mathrm{O} \times \mathrm{OH}(\mathrm{HR})$ images from the two flames. For both flow conditions, the $\mathrm{OH}$ signal shows discontinuities, similar to what has been observed previously with 5kHz OH-PLIF imaging [5]. The $\mathrm{OH}$-containing regions are quite thin and the recirculation zone is void of $\mathrm{OH}$, contrary to premixed flames $[5,25]$ that have significant amounts of $\mathrm{OH}$ inside the recirculation zone. In both H1S1 and H1S2, the $\mathrm{OH}$ regions are overall thin, indicating that the present spray flames have non-premixed flame characteristics. The $\mathrm{OH}$ line follows a relatively straight path along the spray in the inner part of the flame, and a very convoluted part roughly aligned with the shear layer outer 
flame, which is occasionally anchored at the corner of the bluff body. The location of $\mathrm{OH}$ seems more variable in H1S2 than in $\mathrm{H} 1 \mathrm{~S} 1$, which indicates that at a condition far from blow-off (H1S1), the flame sheet is less often extinguished along the spray path.

The region A (inside the recirculation zone) and region $\mathrm{C}$ (in the annular air jet), Row I, Fig 6a, have very low $\mathrm{CH}_{2} \mathrm{O}$ and $\mathrm{OH}$. Occasionally, some formaldehyde appears in the outer recirculation zone (further outwards from the annular air stream), likely to be due to the capture of unburnt or partially-burnt fuel from the wall region where the spray impinges on the wall. Between the spray and the air flow in the annular jet (i.e. region B), intense $\mathrm{CH}_{2} \mathrm{O}$ is visible. Inside the hollow cone spray (region A, i.e. close to the axis), where hot gases recirculate, the $\mathrm{CH}_{2} \mathrm{O}$ signal is virtually zero. There is a transition region that overlaps with the $\mathrm{OH}$ signal and this marks the inner flame branch. This inner branch is likely to be a diffusion flame between evaporated fuel and the air that recirculates that is mixed with hot products from the flame itself. Such a flame is less prone to extinction [26] and this might explain why the outer branch along the shear layer detaches and seems extinguished more often than the inner part. This is also consistent with the temporal analysis of visualisation of blow-off events in this spray flame by $5 \mathrm{kHz} \mathrm{OH}^{*}$ imaging [5] that showed that the inner part of the flame was the last to extinguish.

Individual images vary significantly. Some images show an attached flame (circled in Fig. 6), some present a flame lifted from the bluff-body edge (square), and some show an absence of flame sheet either in the outer shear layer (IIIa, IIb) or the inner recirculation zone (IVb). In the region close to the bluff body and radially outwards from the spray, a significant amount of $\mathrm{CH}_{2} \mathrm{O}$ is present and, when the $\mathrm{OH}$ shows a continuous sheet, the $\mathrm{CH}_{2} \mathrm{O}$ region is bounded by the $\mathrm{OH}$. In conjunction with the laminar flame simulation results, that show that the $\mathrm{CH}_{2} \mathrm{O}$-containing regions are fuel-rich $\left(\xi>\xi_{\mathrm{st}}\right)$, we may conclude that the region between the spray and the annular air is fuel-rich, while the region inside the spray cone is lean. Note 
also that the region between the spray and the annular air occasionally contain no $\mathrm{CH}_{2} \mathrm{O}$ signal. This can be either unburnt fuel or air penetrated through the sheet, both possibilities alluding to an extinction event. Row IV, Fig 6b, shows a region void of both $\mathrm{OH}$ and $\mathrm{CH}_{2} \mathrm{O}$; such regions tend to exist when the $\mathrm{OH}$ has breaks.

The image showing the product $\mathrm{CH}_{2} \mathrm{O} \times \mathrm{OH}$ representing heat release is very strongly correlated to the corresponding $\mathrm{OH}$ image, contrary to premixed flames $[5,17,25]$ that show $\mathrm{OH}$ even in regions very far from the region of coincidence with the $\mathrm{CH}_{2} \mathrm{O}$. This provides support to the use of OH-PLIF for marking reaction zones in such spray flames [5].

\subsection{Averaged $\mathrm{CH}_{2} \mathrm{O} \times \mathrm{OH}$ images}

Figure 7 presents the average images of $\mathrm{OH}, \mathrm{CH}_{2} \mathrm{O}$, and $\mathrm{HR}$ from the two cases. Again, the HR regions are similar to the $\mathrm{OH}$ regions. The region of the recirculation zone between the spray and the shear layer has significant $\mathrm{CH}_{2} \mathrm{O}$. Close to the blow off condition, the flame seems closer to the bluff body, as concluded from the mean $\mathrm{OH}$ and HR images. In addition, higher values of $\mathrm{CH}_{2} \mathrm{O}$ are seen, consistent with the laminar flame simulations that show higher $\mathrm{CH}_{2} \mathrm{O}$ mole fraction at rich mixture fractions as the strain rate increases (Fig. 2).

Figure 8 shows the Abel-transformed mean $\mathrm{OH}^{*}$ chemiluminescence images taken at the same conditions. These two images show very similar results to the mean HR images (Fig. 7). A relatively high intensity region at the inner reaction zone, aligned with the spray, and an outer branch, along the shear layer, are evident by both techniques. The inner branch starts a few $\mathrm{mm}$ from the fuel nozzle and the outer branch seems lifted, but by a distance that is decreasing at the high velocity condition (H1S2). The inner branch seems to have a higher mean heat release rate than the outer branch. These details are seen in both $\mathrm{OH}^{*}$ and $\mathrm{HR}$ data. As the $\mathrm{OH}^{*}$ images do not have interference from Mie scattering or fuel fluorescence, the 
agreement supports the view that the flame shape and location of heat release zones obtained with $\mathrm{CH}_{2} \mathrm{O} \times \mathrm{OH}$ images is trustworthy.

\section{Conclusions}

Joint $\mathrm{CH}_{2} \mathrm{O}$ and $\mathrm{OH}$ PLIF was applied to swirl n-heptane spray flames close to extinction. To assist the image interpretation, laminar counterflow non-premixed flame calculations were also performed. The simulations suggest that the product $\mathrm{X}_{\mathrm{CH} 2 \mathrm{O}} \times \mathrm{X}_{\mathrm{OH}}$ marks relatively well the spatial location of the true heat release, especially at high strain rates, but neglects the heat release in lean mixture fractions, which could amount to about $50 \%$ of the total at low strain rates. The $\mathrm{CH}_{2} \mathrm{O}$-PLIF measurement has limitations due to the interference by fuel and PAH fluorescence. Nevertheless, because the laminar flame simulations show a sharp destruction of $\mathrm{CH}_{2} \mathrm{O}$, soot precursors, and fuel at stoichiometry, we can assume that $\mathrm{CH}_{2} \mathrm{O}$-PLIF marks fuel-rich regions, and that the outline of the $\mathrm{CH}_{2} \mathrm{O}$ region can be thought of as close to the stoichiometric mixture fraction iso-line.

The PLIF showed that the HR regions followed very well the $\mathrm{OH}$ regions, which were thin, characteristic of non-premixed combustion at high strain. With an increase in bulk air velocity, the flame was fragmented more and extinguished more often. The instantaneous images showed great variability and significant parts of the flame sheet could at times be extinguished. The good correlation of the HR image with the $\mathrm{OH}$ signal indicates that highspeed OH-PLIF measurements could be a reliable marker for HR regions in swirling spray flames. Compared with line-of-sight inverse Abel-transformed $\mathrm{OH}^{*}$ chemiluminescence measurements, the $\mathrm{CH}_{2} \mathrm{O} \times \mathrm{OH}$ heat release rate estimation reveals quite similar flame shape and locations.

\section{Acknowledgements}


R. Yuan has been funded by an EPSRC Dorothy Hodgkin Studentship. Dr Balachandran and Mr Dowlut gratefully acknowledge support from EPSRC for research grant EP/G063788/1 and UCL/EPSRC Doctoral Training Account respectively that enabled the measurement methods presented here. 


\section{References}

[1] A. R. Masri, P. A. M. Kalt, Y. M. Al-Abdeli, R. S. Barlow, Combustion Theory and Modelling, 11 (5) (2007) 653-673.

[2] M. Juddoo, A.R. Masri, Combust. Flame, 158 (2011) 902-914.

[3] A.M. Steinberg, I. Boxx, C.M. Arndt, J.H. Frank, W.Meier, Proc. Combust. Inst. 33 (2011) 1663-1672.

[4] S.J. Shanbhogue, S. Husain, T. Lieuwen, Prog. Energy Combust. Sci. 35 (2009) 98-120.

[5] D.E. Cavaliere, J. Kariuki, E. Mastorakos, Flow Turbul. Combust. 91 (2013) 347-372.

[6] R. L. Gordon, A. R. Masri, E. Mastorakos, Combust Theory Modelling, 13 (4) (2009) 645-670.

[7] W. O'Loughlin, A. R. Masri, Flow Turbul. Combust. 89 (2012) 13-35.

[8] A.R. Masri, J. Gounder, W. O' Loughlin, L. DeFina, 7th Mediterranean Combustion Symposium, Sardinia, Italy, (2011).

[9] A. Burkert, W. Paa, M. Reimert, K. Klinkov, C. Eigenbrod, Fuel, 111 (2013) 384-392.

[10] H. Haessler, H. Bockhorn, C. Pfeifer, D. Kuhn, Flow Turbul. Combust. 89 (2012) 249259.

[11] A.J. Donkerbroek, A.P. van Vliet, L.M.T. Somers, P.J.M. Frijters, R.J.H. Klein-Douwel, N.J. Dam, W.L. Meerts, J.J. ter Meulen, Combust. Flame, 157 (2010) 155-166.

[12] M. R. Schrewe, J. B. Ghandhi, Proc. Combust. Inst. 31 (2007) 2871-2878.

[13] H. N. Najm, P. H. Paul, C. J. Mueller, P. S. Wyckoff, Combust. Flame, 113 (1998) 312332.

[14] J. E. Harrington, K. C. Smyth, Chemical Physics Letters, 202 (3-4) (1993) 196-202.

[15] K. Bijjula, D. C. Kyritsis, Proc. Combust. Inst. 30 (2005) 493-500.

[16] R.L. Gordon, A. R. Masri, E. Mastorakos, Combust. Flame, 155 (2008) 181-195.

[17] B.O. Ayoola, R. Balachandran, J.H. Frank, E. Mastorakos, C.F. Kaminski, Combust. Flame, 144 (2006) $1-16$.

[18] P. R. Medwell, B. B. Dally, Combust. Flame, 159 (2012) 3138-3145.

[19] A. Tyliszczak, D.E. Cavaliere, E. Mastorakos, Flow Turbul. Combust. (2013). To appear.

[20] A. Dowlut, T. Hussain, R. Balachandran, 19th International Congress on Sound and Vibration, Lithuania (2012).

[21] R. J. Santoro, AD REPORTS -NTIS- AD A, (1994) 40-43.

[22] L. Petarca, F. Marconi, Combust. Flame, 78 (1989) 308-325. 
[23] Rotexo-Softpredict-Cosilab, GmbH and Co. KG Bad Zwischenahn (Germany), Cosilab Collection, Version 3.0, 2009. Available from: www.SoftPredict.com.

[24] T.J. Held, A.J. Marchese, F.L. Dryer, Combust. Sci. Tech. 123 (1997) 107-146.

[25] J. Kariuki, J.R. Dawson, E. Mastorakos, Combust. Flame, 159 (2012) 2589-2607.

[26] E. Mastorakos, A.M.K.P. Taylor, J.H. Whitelaw, Combust. Flame, 102 (1995) 101-114. 


\section{Tables}

Table 1. Flow conditions. For all, the fuel flow rate was $0.27 \mathrm{~g} / \mathrm{s}$.

\begin{tabular}{llll}
\hline Name & $\boldsymbol{U}_{\boldsymbol{a}}[\mathbf{m} / \mathbf{s}]$ & $\boldsymbol{U}_{\boldsymbol{a}} / \boldsymbol{U}_{\boldsymbol{B} \boldsymbol{O}}$ & $\boldsymbol{\Phi}$ \\
\hline $\mathrm{H} 1 \mathrm{~S} 1$ & 17.1 & 0.75 & 0.32 \\
$\mathrm{H} 1 \mathrm{~S} 2$ & 20.0 & 0.88 & 0.27 \\
$\mathrm{H} 1 \mathrm{~B}$ & 22.8 & 1 & 0.24 \\
\hline
\end{tabular}




\section{Figures}
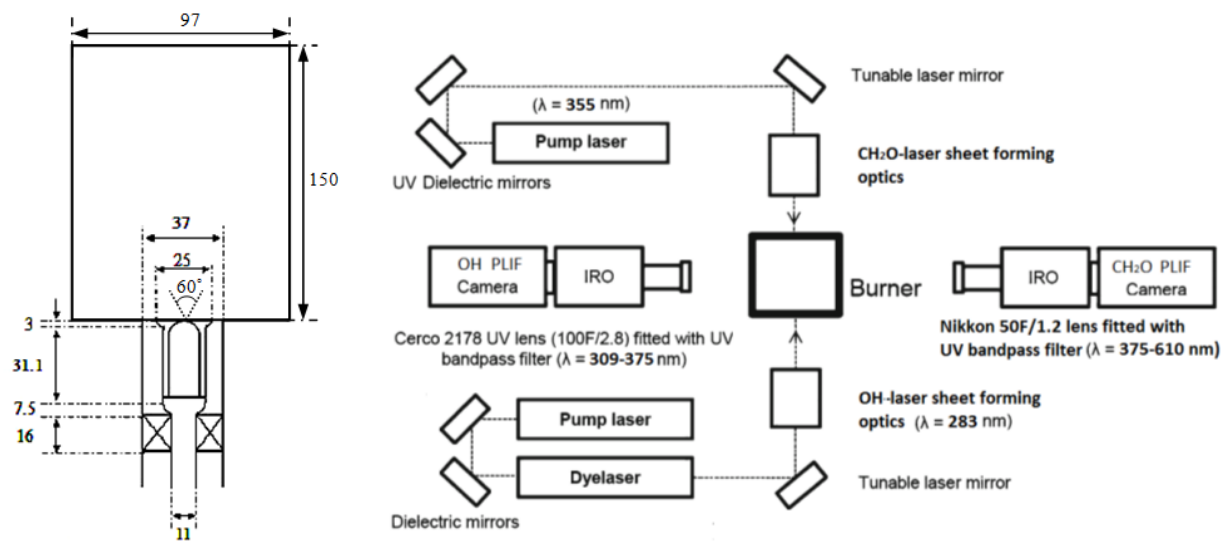

Figure 1: The burner (left) and laser system (right) schematic. 


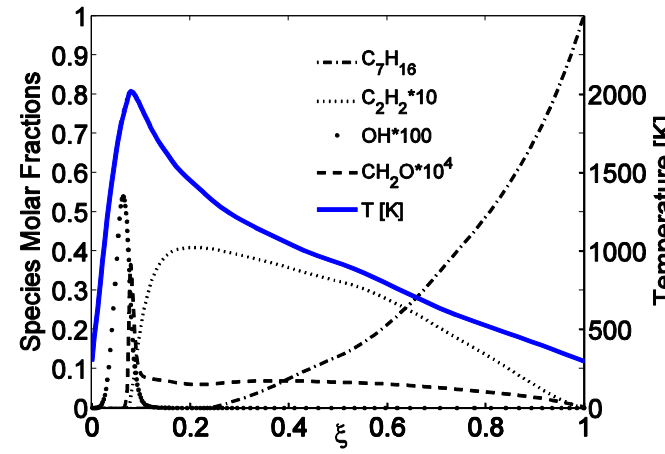

(a)

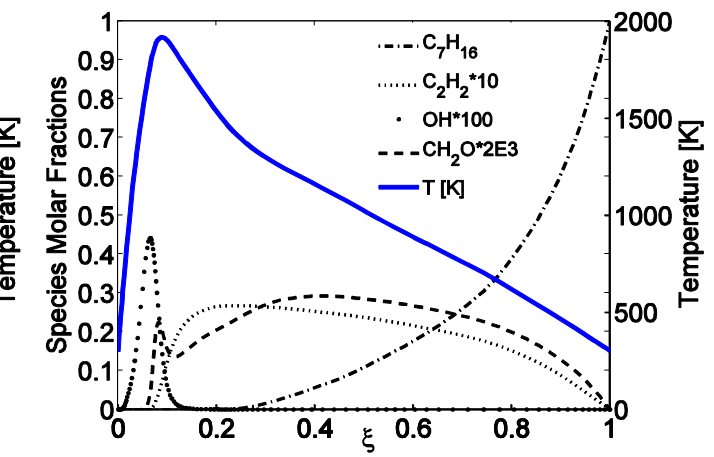

(b)

Figure 2: Temperature and various species molar fractions $v s$. mixture fraction for strain rate (a) $100 \mathrm{~s}^{-1}$ and (b) $500 \mathrm{~s}^{-1}$. 


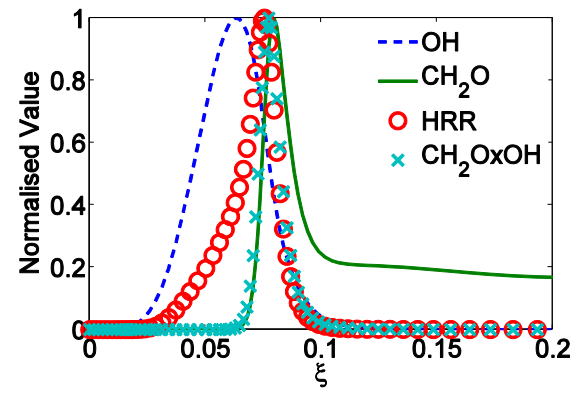

(a)

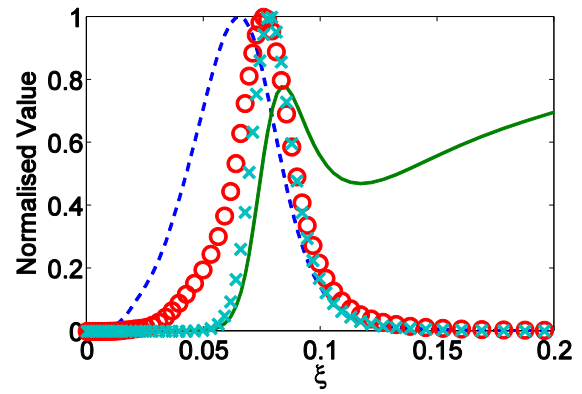

(b)

Figure 3: Normalised mole fractions of $\mathrm{OH}$ and $\mathrm{CH}_{2} \mathrm{O}$, normalised $\mathrm{HRR}$, and normalised $\mathrm{X}_{\mathrm{CH} 2 \mathrm{O}} \times \mathrm{X}_{\mathrm{OH}}$ at strain rate (a) $100 \mathrm{~s}^{-1}$ and (b) $500 \mathrm{~s}^{-1}$. 


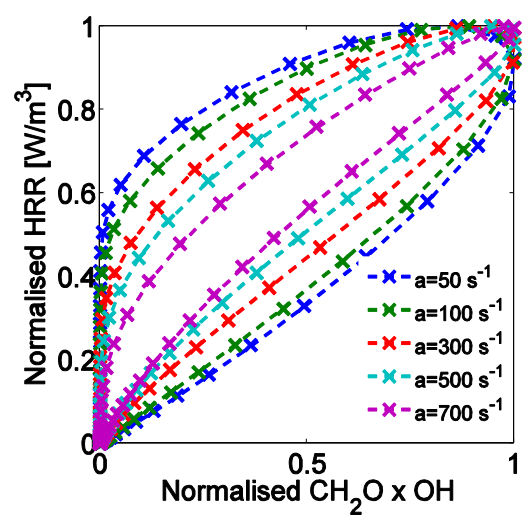

(a)

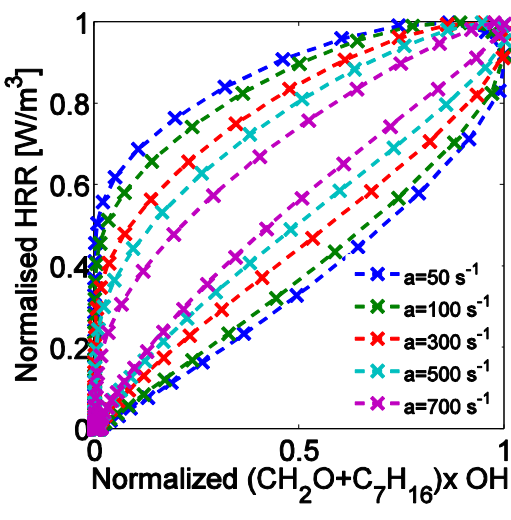

(b)

Figure 4: (a) HRR vs. $\mathrm{X}_{\mathrm{CH} 2 \mathrm{O}} \times \mathrm{X}_{\mathrm{OH}}$ (b) HRR vs. $\left(\mathrm{X}_{\mathrm{CH} 2 \mathrm{O}}+\mathrm{X}_{\mathrm{C} 7 \mathrm{H} 16}\right) \times \mathrm{X}_{\mathrm{OH}}$ for the indicated strain rate. 


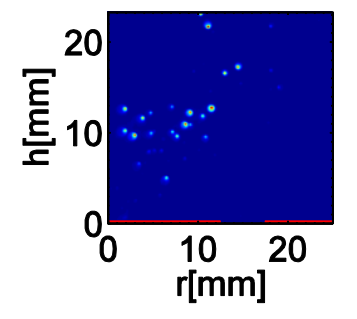

(a)

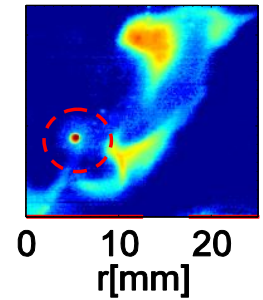

(b)

Figure 5: (a) Un-ignited spray, $\mathrm{CH}_{2} \mathrm{O}$ image; (b) example $\mathrm{CH}_{2} \mathrm{O}$ image of $\mathrm{H} 1 \mathrm{~S} 1$ flame. The colour map is logarithmic. 


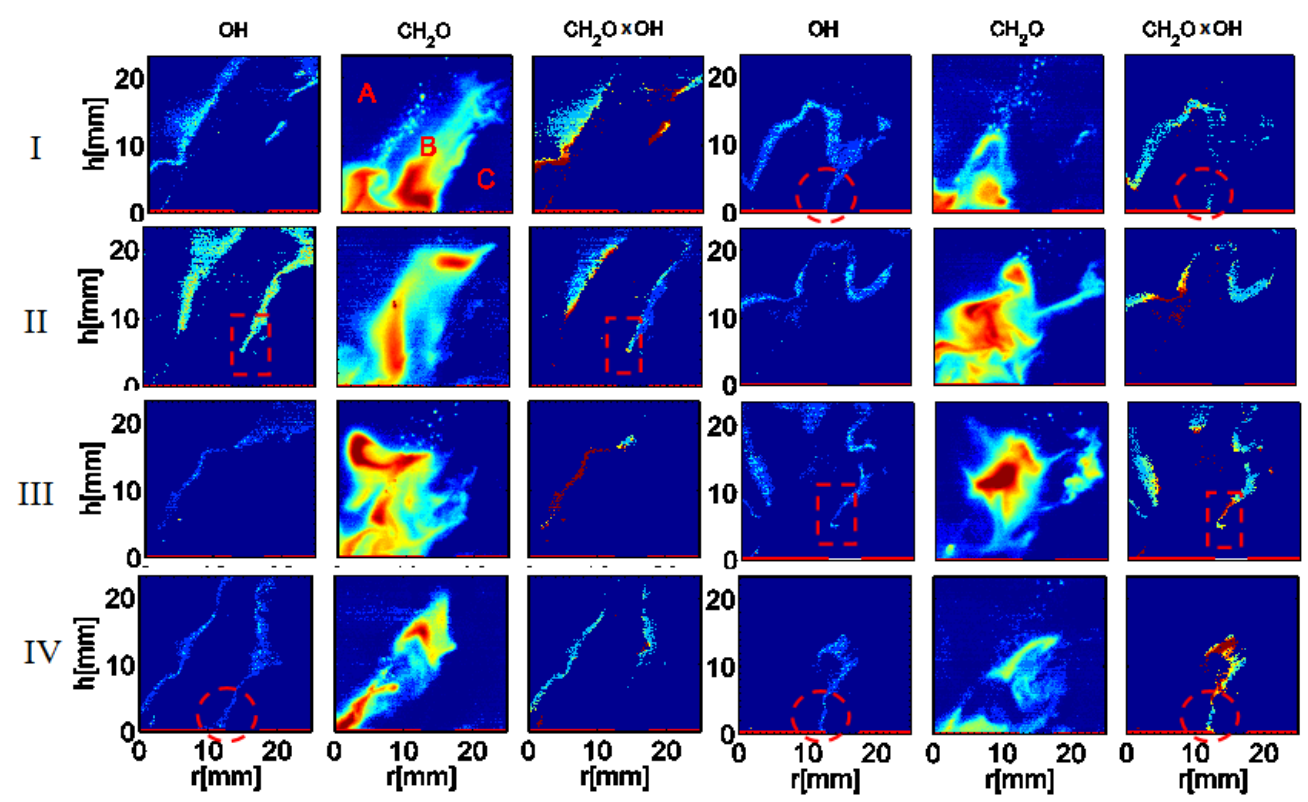

(a)

(b)

Figure 6: Instantaneous $\mathrm{CH}_{2} \mathrm{O}, \mathrm{OH}$, and images for $\mathrm{H} 1 \mathrm{~S} 1$ (a) and $\mathrm{H} 1 \mathrm{~S} 2$ (b). I-IV are discussed in the text. The $\mathrm{CH}_{2} \mathrm{O}$ image colour map is logarithmic. 


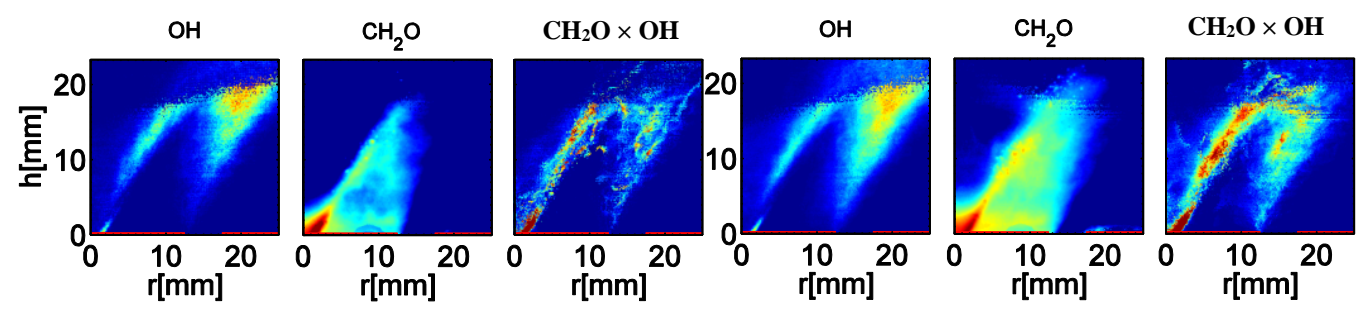

(a)

(b)

Figure 7: Mean $\mathrm{OH}, \mathrm{CH}_{2} \mathrm{O}$, and $\mathrm{CH}_{2} \mathrm{O} \times \mathrm{OH}$ for (a) $\mathrm{H} 1 \mathrm{~S} 1$ and (b) $\mathrm{H} 1 \mathrm{~S} 2$. 


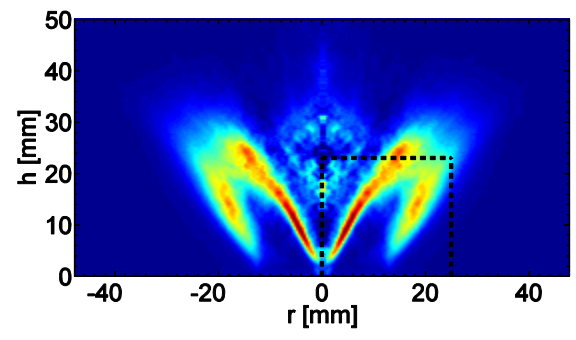

(a)

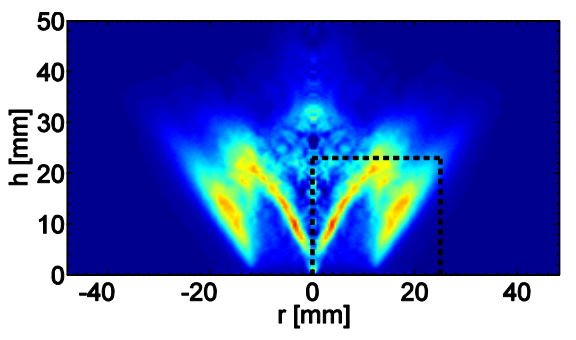

(b)

Figure 8: Inverse Abel-transformed mean $\mathrm{OH}^{*}$ chemiluminescence images: (a) H1S1 and (b) H1S2. The black square marks the PLIF region. 


\section{Figure captions}

Figure 1: The burner (left) and laser system (right) schematic.

Figure 2: Temperature and various species molar fractions $v s$. mixture fraction for strain rate (a) $100 \mathrm{~s}^{-1}$ and (b) $500 \mathrm{~s}^{-1}$.

Figure 3: Normalised mole fractions of $\mathrm{OH}$ and $\mathrm{CH}_{2} \mathrm{O}$, normalised $\mathrm{HRR}$, and normalised $\mathrm{X}_{\mathrm{CH} 2 \mathrm{O}} \times \mathrm{X}_{\mathrm{OH}}$ at strain rate (a) $100 \mathrm{~s}^{-1}$ and (b) $500 \mathrm{~s}^{-1}$.

Figure 4: (a) HRR vs. $\mathrm{X}_{\mathrm{CH} 2 \mathrm{O}} \times \mathrm{X}_{\mathrm{OH}}$ (b) HRR vs. $\left(\mathrm{X}_{\mathrm{CH} 2 \mathrm{O}}+\mathrm{X}_{\mathrm{C} 7 \mathrm{H} 16}\right) \times \mathrm{X}_{\mathrm{OH}}$ for the indicated strain rate.

Figure 5: (a) Un-ignited spray, $\mathrm{CH}_{2} \mathrm{O}$ image; (b) example $\mathrm{CH}_{2} \mathrm{O}$ image of $\mathrm{H} 1 \mathrm{~S} 1$ flame. The colour map is logarithmic.

Figure 6: Instantaneous $\mathrm{CH}_{2} \mathrm{O}, \mathrm{OH}$, and $\mathrm{CH}_{2} \mathrm{O} \times \mathrm{OH}$ images for $\mathrm{H} 1 \mathrm{~S} 1$ (a) and $\mathrm{H} 1 \mathrm{~S} 2$ (b). I-IV are discussed in the text. The $\mathrm{CH}_{2} \mathrm{O}$ image colour map is logarithmic.

Figure 7: Mean $\mathrm{OH}, \mathrm{CH}_{2} \mathrm{O}$, and $\mathrm{CH}_{2} \mathrm{O} \times \mathrm{OH}$ for (a) $\mathrm{H} 1 \mathrm{~S} 1$ and (b) $\mathrm{H} 1 \mathrm{~S} 2$.

Figure 8: Inverse Abel-transformed mean $\mathrm{OH}^{*}$ chemiluminescence images: (a) H1S1 and (b) H1S2.The black square marks the PLIF region. 